Check for updates

Cite this: RSC Adv., 2017, 7, 26551

Received 21st March 2017

Accepted 12th May 2017

DOI: $10.1039 / \mathrm{c} 7 \mathrm{ra03288a}$

rsc.li/rsc-advances

\section{In vitro study of novel microparticle based silk fibroin scaffold with osteoblast-like cells for load- bearing osteo-regenerative applications $\uparrow$}

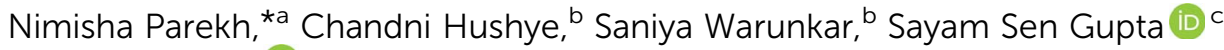 \\ and Anuya Nisal (iD *a
}

\begin{abstract}
Silk Fibroin (SF) is today considered to be one of the most favorable materials for bone tissue engineering. We have prepared novel SF microparticle based 3D scaffolds, with appropriate pore size, pore interconnectivity and porosity, excellent mechanical properties and tunable bioresorption, while retaining the inherent biocompatibility of SF. These properties make them ideal candidates for osteoregenerative applications. Here, we report the in vitro cell viability, cell adhesion and proliferation with osetoblastic differentiation of MG 63 osteoblast-like cell line on these scaffolds. In addition, we have also modified the surface of these scaffolds using collagen type I and chitosan biopolymers. Our results show that although the SF scaffold does support in vitro cell attachment, proliferation and differentiation, this performance can be further enhanced using the surface coating approach. Also, the ALP activity and bone mineralization was found to be particularly superior in the chitosan modified scaffolds.
\end{abstract}

\section{Introduction}

Bone tissue engineering (BTE) has emerged as a promising method for accelerated healing of damaged bone tissues. ${ }^{1}$ BTE involves use of a three-dimensional scaffold that provides the support for cell attachment and natural tissue formation, thus mimicking the natural extracellular matrix. There are, therefore, stringent requirements on the properties of the scaffold that can be used in BTE. The ideal scaffold should have a threedimensional architecture with optimum pore size and pore volume for efficient diffusion and/or migration of nutrients and cells. Secondly, it must have appropriate mechanical strength to provide structural rigidity and support. Thirdly, the scaffold must give the proper chemical, biological and morphological clues that will enable in the efficient functioning of the cells for formation of new tissue. ${ }^{2-4}$ The main challenge, therefore, lies in the development of a functionalizable biocompatible 3D scaffold that can promote cell adhesion by specific cell-matrix interactions.

Calcium phosphate and bioresorbable bioactive glass-based micro-porous ceramic scaffolds have been extensively explored for use in BTE. ${ }^{5}$ However, they are limited by their brittleness. In contrast, variety of natural and synthetic polymeric 3D scaffolds

\footnotetext{
${ }^{a}$ Polymer Science and Engineering Dept., National Chemical Laboratory, HomiBhabha Road, Pune-411008, India.E-mail: n.parekh@ncl.res.in; aa.nisal@ncl.res.in

${ }^{b}$ Department of Zoology, Poona College, Camp, Pune - 411001, India

${ }^{c}$ Department of Chemical Sciences, Indian Institute of Science and Educational Research, Mohanpur - 741246, Kolkata, India

$\dagger$ Electronic supplementary information (ESI) available: Comparative data of scaffolds and comparative image of cell morphology. See DOI: 10.1039/c7ra03288a
}

have been extensively explored for BTE and they exhibit better biocompatibility and mechanical properties., ${ }^{\mathbf{3 , 6}}$ However, polymer-based matrices typically do not possess the mechanical properties of ceramics and rapidly degrade in vivo. Thus they remain nondurable for load bearing applications required in BTE. Recently, a lot of interest is focused on composite materials, which attempt to combine advantages of both polymers and ceramics. However, a 3D scaffold composed of $100 \%$ biopolymer having the properties of composite materials is desirable.

In this context, from the last two decades, silk fibroin (SF) has emerged as a promising material for BTE on account of its excellent biocompatibility, tuneable bioresorption, easy processibility and thermo-mechanical stability. ${ }^{\mathbf{1 , 7 - 9}}$ SF-scaffolds have shown to induce bone formation, stimulate osteogenic differentiation of human mesenchymal stem cells, ${ }^{\mathbf{1 0}-13}$ and support tissue vascularisation in in vitro models of BTE. ${ }^{14-16} \mathrm{SF}$ can be produced in large commercial quantities with control on quality. It allows easy chemical modification ${ }^{\mathbf{1 7}}$ that is required to obtain required functionality and can also be processed into 3D materials such as hydrogels, sponges, fibers, microspheres, and electrospun fiber mats. ${ }^{\mathbf{1 1 8 - 2 2}}$ The unique mechanical properties and tunable bioresorption rate of these 3D scaffolds allows attachment, proliferation and differentiation of mesenchymal stem cells along the osteogenic lineage for BTE. The efficacy of these 3D scaffolds from SF gets enhanced when they are surface functionalized with integrin binding RGD motifs, collagen, chitosan, gelatin and growth factors like transforming growth factor- $\beta$ (TGF- $\beta$ ), VEG-F and bone morphogenic protein (BMPs). ${ }^{23-25}$ However, the main limitation of the scaffolds 
discussed above is that they are mostly soft in nature and do not have high load bearing capacity which is essential for BTE. Recently, high strength SF scaffold for BTE which possess high load bearing ability, has been reported by a few groups. ${ }^{26-28} \mathrm{Ak}$ et al. have described a novel method of cryo-gelation using a cross-linker molecule. ${ }^{27}$ Also, Mandal et al. have described scaffolds prepared using salt leaching and reinforced with SF microfibers. ${ }^{26}$ We have recently developed novel processing protocols to produce unique 3D scaffolds of silk fibroin using SF micro-particles. ${ }^{29,30}$ Here, the SF micro-particles are produced by collection of drops of SF solution in a methanol bath. These micro-particles are then fused together using a dilute solution of SF in water. This novel protocol has then been used to produce 3D scaffolds with excellent mechanical properties (dry compression modulus 10-100 MPa, wet compression modulus of $25 \mathrm{MPa}$ ), which is one of the main prerequisite for BTE and a property that is lacking in almost all SF based scaffold. The bulk porosity in scaffolds is in the range of $40-60 \%$ and the pore sizes are of the order of $50-500 \mu \mathrm{m}$. It has been well documented that microparticle based scaffolds have improved pore interconnectivity and better control on pore size and porosity. ${ }^{31}$ The conformation of SF protein in the microparticle can be controlled, which implies that the bioresorption of the scaffold can be tuned. In addition to these advantages, the methodology of scaffold fabrication is flexible enough to incorporate various functionalities such as growth factors, fillers and drug molecules amongst others. These properties make this scaffold unique for BTE in comparison to other scaffolds recently reported. (ESI Fig. S1, $\uparrow$ for a comparison of properties with other load bearing SF-scaffolds).

In this paper, we explore the in vitro cell morphology, cell viability, cell adhesion and proliferation with osteoblastic differentiation of MG 63 osteoblast-like cell line on these scaffolds containing $100 \% \mathrm{SF}$ and having high mechanical strengths. In addition, we report a simple method to enhance the performance of this SF-scaffold for BTE by surface coating of the scaffolds with collagen type I and chitosan biopolymers. Collagen, a dominant component of the ECM in the bone tissue, is known to favour cell adhesion and provide the right chemical cues for osteogenic differentiation. ${ }^{32-34}$ Chitosan on the other hand, is known for its inherent osteogenic potential and has been a well-documented biopolymer for BTE. ${ }^{35-39} \mathrm{We}$ show the in vitro cell viability, cell adhesion and proliferation with osetoblastic differentiation of MG 63 osteoblast-like cells in this collagen (Coll-SF)/chitosan (CS-SF) coated SF scaffolds and compare their performance to the uncoated SF-scaffolds.

\section{Materials and methods}

\section{SF-scaffold preparation}

SF-scaffold has been prepared as per the protocol mentioned in our patent applications..$^{29,30}$ In brief, $4 \mathrm{~mL}$ syringe was filled with the SF-HFIP solution. A syringe pump with an infusion rate of 1 $\mathrm{mL} \min ^{-1}$ was used and the drops of SF-HFIP solution were collected in a stirred methanol coagulant bath. The particles so formed were kept in methanol bath for $3 \mathrm{~h}$. Fresh methanol was then replenished after $3 \mathrm{~h}$ and the particles were further

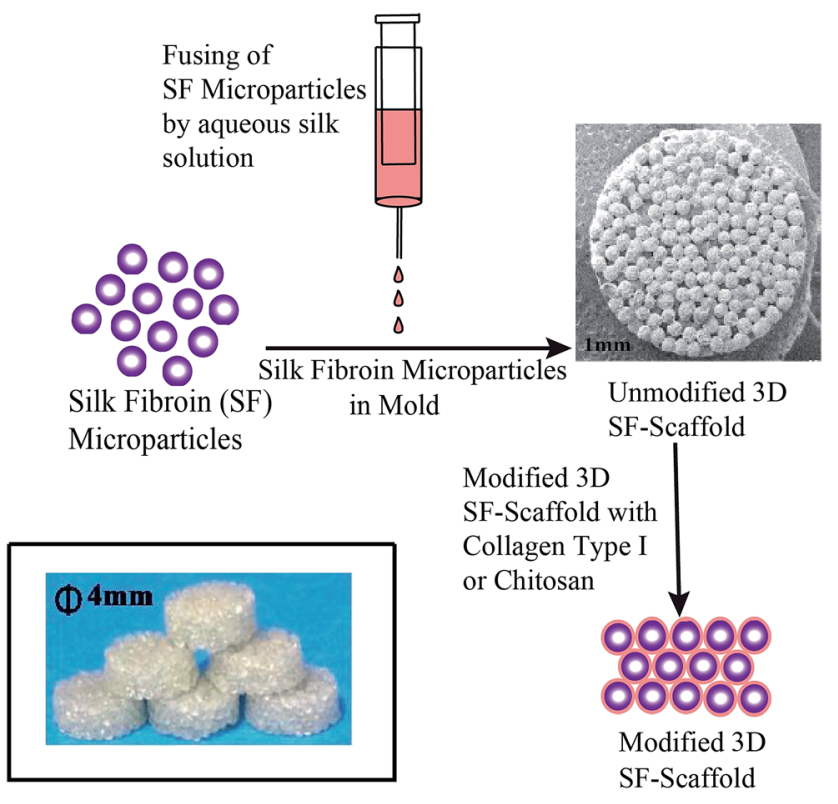

Fig. 1 Schematic representation of SF-scaffold preparation and surface modification.

incubated in methanol for $12 \mathrm{~h}$. The micro-particles were allowed to air dry and the 3D SF-scaffold was prepared by fusing these SF micro-particles in a cylindrical mold using aqueous SF solution as shown in Fig. 1.

\section{Surface modification}

For collagen. $1 \mathrm{mg} \mathrm{mL} \mathrm{m}^{-1}$ sterile collagen solution (Sigma) was diluted 10 times using sterile DI water. A SF-scaffold was kept in the well of a 96 well plate. $100 \mu \mathrm{L}$ of the collagen solution prepared was added to each well and incubated at room temperature for $12 \mathrm{~h}$. The remaining solution was then pipetted out and the scaffold was dried at $4{ }^{\circ} \mathrm{C}$ for $12 \mathrm{~h}$. The scaffold was stored at $4{ }^{\circ} \mathrm{C}$ until further use.

For chitosan. 1 wt $\%$ chitosan (Sigma) solution was prepared in $0.05 \mathrm{M}$ acetic acid. $100 \mu \mathrm{L}$ of this chitosan solution was added per scaffold to the SF-scaffold and kept at $60{ }^{\circ} \mathrm{C}$ for 20 minutes in an oven to obtain dry CS-SF scaffold.

\section{Surface characterisation by scanning electron microscopy}

The uncoated as well as coated SF scaffolds were observed for surface features using a Scanning Electron Microscope (SEM). The samples were sputter coated with $5 \mathrm{~nm}$ gold $(\mathrm{Au})$ coating using a Polaron SC 6420 sputter coater prior to SEM imaging. Image was captured on a Quanta 200 3D SEM equipped with a tungsten filament gun, operating at WD $10.6 \mathrm{~mm}$ and $20 \mathrm{kV}$. Images of representative areas at suitable magnification were captured.

\section{Cell culture}

MG63 human osteoblast-like cells were purchased from National Centre for Cell Science (NCCS), Pune, Maharastra, India. Cells were maintained in DMEM (Gibco) with 10\% FBS (Gibco). 


\section{Cell viability}

Trypan blue assay. MG 63 cells were maintained in complete media containing DMEM with $10 \%$ FBS. Before seeding the cells, scaffolds were incubated in complete media at $37^{\circ} \mathrm{C}$ with $5 \% \mathrm{CO}_{2}$ for $12 \mathrm{~h} .5 \times 10^{4}$ cells per scaffold in $100 \mu \mathrm{L}$ of complete media were seeded on SF, Coll-SF and CS-SF scaffolds. Cells were trypsinized and counted on the $1^{\text {st }}, 3^{\text {rd }}, 5^{\text {th }}$ and $7^{\text {th }}$ day in Neubauer chamber by using standard trypan blue method.

Live/dead assay. MG 63 cells were seeded on SF, Coll-SF, CSSF scaffolds at a density of $5 \times 10^{4}$ in DMEM containing $10 \%$ FBS. Cells were incubated at $37{ }^{\circ} \mathrm{C}$ with $5 \% \mathrm{CO}_{2}$ upto 7 days. During incubation, on the $1^{\text {st }}, 3^{\text {rd }}, 5^{\text {th }}$ and $7^{\text {th }}$ day, cells were stained with live/dead staining solution that comprises of $10 \mu \mathrm{L}$ of $7.5 \mathrm{mM}$ propidium iodide and $1 \mu \mathrm{L}$ of $0.67 \mathrm{mM}$ acridine orange (both stock were prepared in PBS) in $1 \mathrm{~mL}$ of DMEM containing $10 \%$ FBS. Cells were incubated at $37^{\circ} \mathrm{C}$ with $5 \% \mathrm{CO}_{2}$ for $\sim 25$ minutes. Later, cells were washed two times with PBS and images were captured by epi-fluorescence microscopy using Axio Observer Z1 Carl Zeiss Microscope.

\section{Cell proliferation}

Cell proliferation was determined by MTT (3-(4,5-dimethylthiazol2-yl)-2,5-diphenyltetrazolium bromide) assay. Before seeding the cells, SF, Coll-SF and CS-SF scaffolds were incubated in complete media at $37{ }^{\circ} \mathrm{C}$ with $5 \% \mathrm{CO}_{2}$ for $12 \mathrm{~h}$. MG 63 cells were seeded in a flat-bottomed non-adhesive 96-well plate at a density of $5 \times 10^{4}$ cells per scaffold in $100 \mu \mathrm{L}$ of complete media. The plate was incubated at $37{ }^{\circ} \mathrm{C}$ with $5 \% \mathrm{CO}_{2}$ for $24 \mathrm{~h}$. During incubation, on the $1^{\text {st }}, 3^{\text {rd }}, 5^{\text {th }}$ and $7^{\text {th }}$ day, the media was replaced with filter sterilized MTT $\left(0.45 \mathrm{mg} \mathrm{mL}^{-1}\right)$ prepared in DMEM containing $10 \% \mathrm{FBS}$ and further incubated for $4 \mathrm{~h}$ at $37^{\circ} \mathrm{C}$ with $5 \% \mathrm{CO}_{2}$. MTT reagent was replaced by DMSO $100 \mu \mathrm{L}$ per well and kept at $37{ }^{\circ} \mathrm{C}$ with $5 \% \mathrm{CO}_{2}$ for $20-25$ minutes. Addition of DMSO dissolves the formazan crystals formed by reaction of sample with MTT and the developed color was measured at $550 \mathrm{~nm}$ using a microtitre plate reader (Multiskan EX, Thermo Scientific). Each absorbance was taken to be the mean of triplicate measurements.

\section{Cell morphology by actin cytoskeleton staining}

MG 63 cells were seeded on SF, Coll-SF, CS-SF scaffolds at a density of $5 \times 10^{4}$ in DMEM containing $10 \%$ FBS. Cells were incubated at $37{ }^{\circ} \mathrm{C}$ with $5 \% \mathrm{CO} 2$ up to 7 days. During incubation, on the $3^{\text {rd }}, 5^{\text {th }}$ and $7^{\text {th }}$ day, actin cytoskeleton staining was performed using the following protocol: scaffolds were washed with PBS followed by the cell fixation with $4 \%$ paraformaldehyde for 15 minutes at room temperature. The cells were later washed with PBS two times and $0.1 \%$ Triton X-100 (Sigma-Aldrich) for 5 minutes. The cells were again subjected to PBS washing two times and incubated with 5\% BSA for 20 minutes at room temperature to avoid non-specific binding. Actin filaments were stained by $1: 100$ dilution of alexafluor 488 phalloidin (Thermo Fisher Scientific) prepared in PBS and incubated for 30 minutes in dark at room temperature. Cell's nucleus was counter stained with DAPI at $300 \mathrm{nM}$ concentration for 4 minutes at room temperature and washed with PBS.
Images were captured by epi-fluorescence microscopy using Axio Observer Z1 Carl Zeiss Microscope.

\section{Osteogenic differentiation by alkaline phosphatase (ALP) assay}

Alkaline phosphatase (ALP) activity was assayed using colorimetric ALP kit (Abcam, U.K.). Briefly, MG 63 cells were seeded on a SF, Coll-SF, CS-SF scaffolds at a density of $5 \times 10^{4}$ cells per scaffold in $10 \mu \mathrm{L}$ of complete media. The cells were allowed to be settled for $5-7$ minutes at $37{ }^{\circ} \mathrm{C}$ with $5 \% \mathrm{CO}_{2}$. The additional 90 $\mu \mathrm{L}$ media for cells was then added and the cell culture plate was then incubated at $37{ }^{\circ} \mathrm{C}$ with $5 \% \mathrm{CO}_{2}$ for 7 days. On the second day of the experiment, seeding media was replaced with osteogenic differentiation media (Invitrogen). During incubation, on the $3^{\text {rd }}, 5^{\text {th }}$ and $7^{\text {th }}$ day, spent media from cell seeded scaffolds was collected and $80 \mu \mathrm{L}$ of the spent media was incubated with 50 $\mu \mathrm{L}$ of $p$-nitrophenyl phosphate $(5 \mathrm{mM})$ solution at room temperature for $1 \mathrm{~h}$ in the dark. At the end of the incubation, enzyme activity was stopped by adding $20 \mu \mathrm{L}$ of stop solution. Simultaneously, standard curve was plotted (ESI Fig. S2 $\dagger$ ) as per manufacturer's instruction. The amount of $p$-nitro-phenol produced was measured by measuring absorbance at $405 \mathrm{~nm}$.

\section{Extracellular mineral $\left(\mathrm{Ca}^{+2}\right)$ deposition and quantification}

Mineralized calcium deposition at the end of $7^{\text {th }}$ day was analyzed with Alizarin Red S staining. In brief, MG 63 cells were seeded on a SF, Coll-SF, CS-SF scaffolds at a density of $5 \times 10^{4}$ cells per scaffold in $10 \mu \mathrm{L}$ of complete media. The cells were allowed to be settled for $5-7$ minutes at $37{ }^{\circ} \mathrm{C}$ with $5 \% \mathrm{CO}_{2}$. The additional $90 \mu \mathrm{L}$ media for cells was then added and the cell culture plate was then incubated at $37{ }^{\circ} \mathrm{C}$ with $5 \% \mathrm{CO}_{2}$ for 7 days. On the day after seeding, the media was replaced with osteogenic differentiation media (Invitrogen). On $7^{\text {th }}$ day, scaffolds were fixed with $4 \%$ formaldehyde at room temperature for $10 \mathrm{~min}$. They were later washed with PBS and then stained with 2\% Alizarin Red (Sigma) solution for 20 minutes at room temperature. After staining, the scaffolds were washed two times with DI water. Calcium deposition was observed under bright field by Axio Observer Z1 from Carl Zeiss.

Ca deposition was further confirmed by quantifying the total calcium content. ${ }^{23,40}$ In brief, at the end of $7^{\text {th }}$ day, scaffolds were washed with PBS and the deposited calcium was extracted with $0.5 \mathrm{~mL}$ of $5 \%$ trichloroacetic acid for 30 minutes. At the end of incubation, Ca was quantified using $O$-cresolphthalein complexone colorimetric assay (Sigma).

The developed color for scaffolds seeded with cells were measured at $575 \mathrm{~nm}$ and the absorbance at $575 \mathrm{~nm}$ for scaffolds that were not seeded with cells was subtracted to quantify the Ca content. Standard calibration curve was prepared as per manufacturer instructions (ESI Fig. S3†).

\section{Results and discussion}

\section{D microparticle SF-scaffold}

Silk fibroin based scaffolds have been prepared using a variety of methods like lyophilisation, salt leaching, electrospinning, 
SF

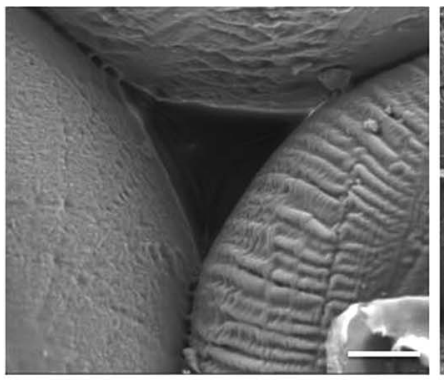

Coll-SF

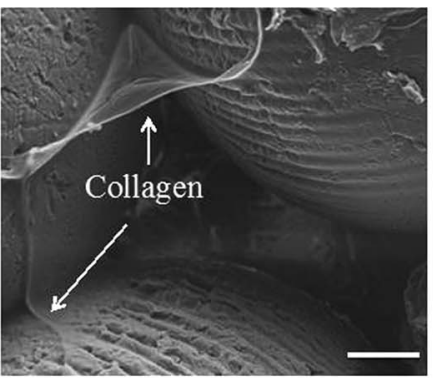

CS-SF

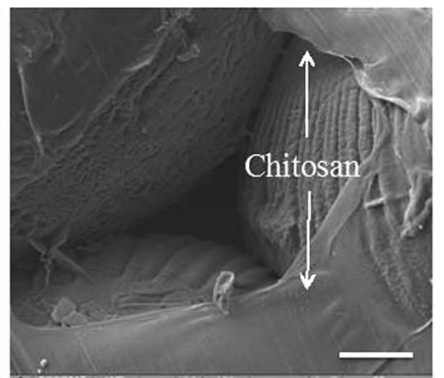

Fig. 2 SEM images of SF, Coll-SF and CS-SF and all images were at the scale bar is $50 \mu \mathrm{m}$.

ice crystal templating, etc. These materials have shown promise in BTE applications. In this report, we use 3D microparticle SFscaffold which was prepared using a methodology developed in our laboratory. Preliminary studies on the physical properties of this 3D microparticle SF-scaffold (such as mechanical integrity, pore size and pore volume and rate of bioresorption) match the requirements for a scaffold in BTE (ESI Fig. S1 $\dagger$ ).

However, the hydrophobic nature of SF results in limited cellbiomaterial interaction. We have introduced surface modification of the SF-scaffold to further improve cell adhesion and proliferation. Our process involves coating the surface of this microparticle scaffold using collagen type I and chitosan biopolymers that are known to enhance cell adhesion and proliferation. The method involved incubating the SF-scaffolds with the biopolymer and allowing them to anneal and coat the surface. The morphological features of surface coating were studied using Scanning Electron Microscopy (SEM). Fig. 2 shows the SEM images of SF scaffold (SF) and surface modified scaffolds treated with collagen (Coll-SF) and chitosan (CS-SF). The SEM images of SF scaffold (Fig. 2) display mono-disperse microparticles packed together in hexagonal packing. The surface of SF micro-particles shows presence of dried SF solution used to fuse these particles together. The interparticle pore sizes are clearly visible and are of the order of $100 \mu \mathrm{m}$. The collagen modified SF scaffold shows presence of additional material domains dispersed throughout the surface (Fig. 2). These could be attributed to the collagen coating. Similar material domains were also observed in the chitosan treated scaffold (Fig. 2). It has been found that a minimum pore size of 30 microns is necessary for effective cell migration and colonization. ${ }^{41}$ As can be seen in the Fig. 2, the method used for coating here does not alter the pore size of the scaffold. This implies that the surface modification technique is not expected to inhibit transport of nutrients and waste diffusion or cell migration in the scaffold.

\section{Cell viability and proliferation studies}

The uncoated and coated SF scaffolds were evaluated using in vitro cell culture studies. MG-63 cells, was chosen for this study as it has a high proliferation rate. In vitro studies performed in a 7 day experiment are therefore sufficient to provide reliable and sensitive information on performance of this material as a possible scaffold for BTE. ${ }^{42-44}$ Cell viability of MG 63 is

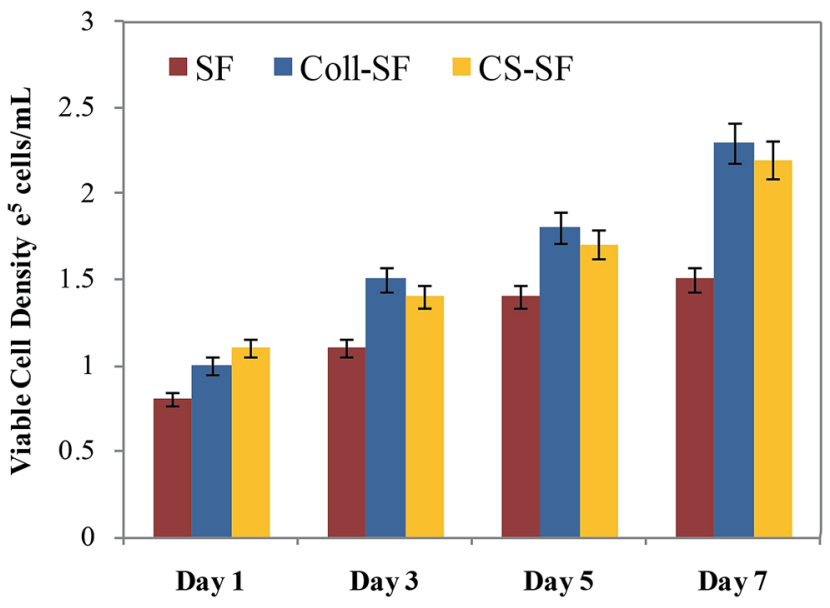

Fig. 3 Viable MG 63 cell density counted by trypan blue dye exclusion method (data are represented as the mean \pm SD of two independent experiments).

prerequisites for further application of any developed material and hence it was quantitatively assayed by using trypan blue dye exclusion method and qualitatively by performing live/dead imaging using AO and PI stains. Fig. 3 shows the viable cell count on the $1^{\text {st }}, 3^{\text {rd }}, 5^{\text {th }}$ and $7^{\text {th }}$ day after seeding the MG 63 on SF, Coll-SF and CS-SF scaffolds and it shows that SF scaffold does support attachment of the MG63 cells.

Also, as the experiment progresses the number of viable cells on the SF-scaffold increases. However, coating or surface modifying the scaffolds resulted in increased number of viable cells. On a given day of the experiment, the Coll-SF scaffolds and CS-scaffolds have a higher number of viable cells as compared to the uncoated SF scaffold. However, viability of the cells on the Coll-SF and CS-SF scaffold is comparable and no significant differences between these two scaffolds were observed here.

The trends observed in cell viability were further corroborated using live-dead assay. Fig. 4 shows the individual channel images of AO and PI on the $1^{\text {st }}, 3^{\text {rd }}, 5^{\text {th }}$ and $7^{\text {th }}$ day after seeding the MG 63 on SF, Coll-SF and CS-SF scaffold. For the SF-scaffold, MG 63 cells did adhere and found to be live to the micro-particle surface. Also, there were increased number of viable cells visible as the days progressed. Insignificant or no red coloured spots in these images indicate absence of dead cells on these scaffolds. 

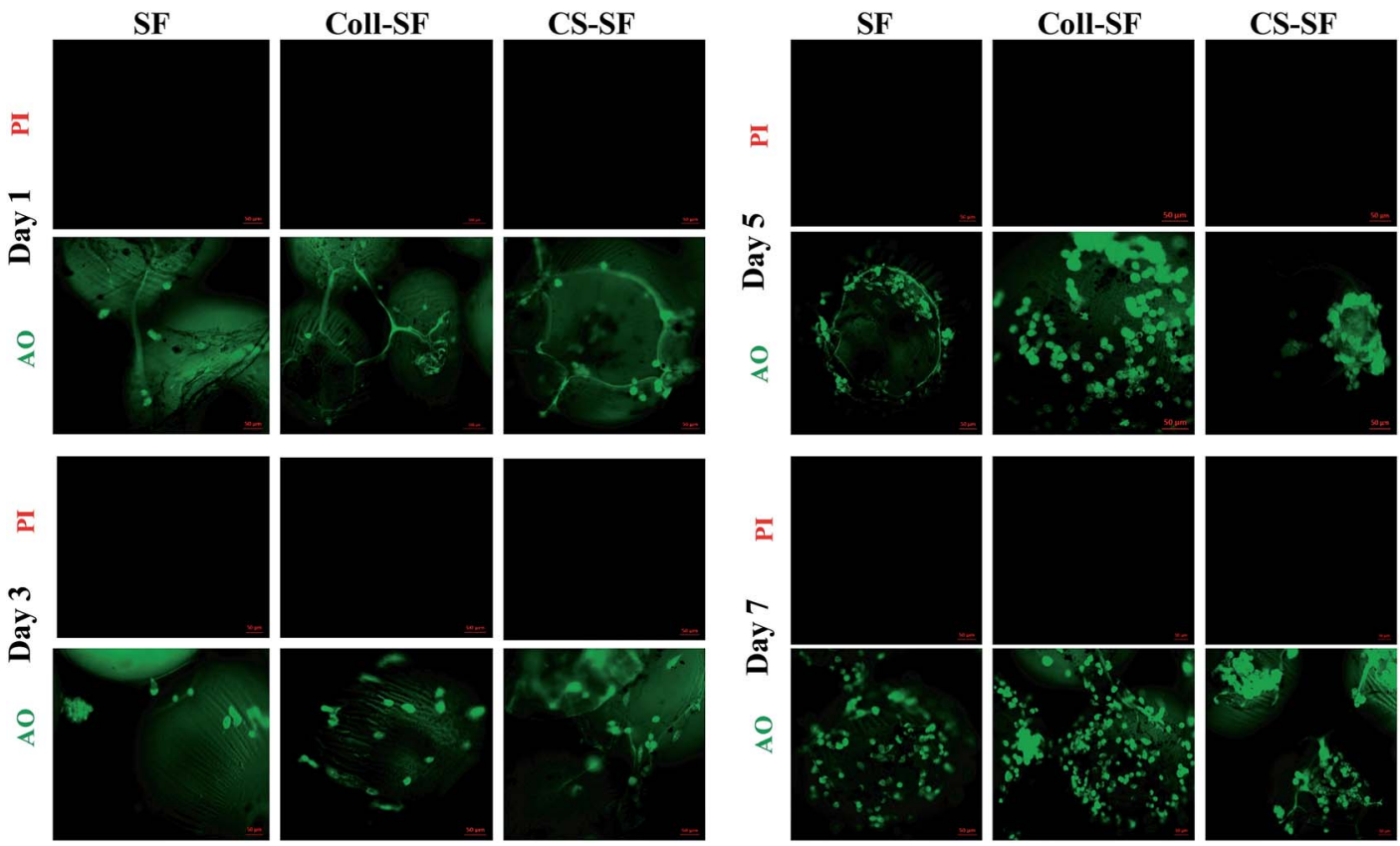

Fig. 4 Epi-fluorescence images of live (green) and dead (red) MG 63 cells grown on SF, Coll-SF and CS-SF. All images were taken at same exposure time and scale bar is $50 \mu \mathrm{m}$.

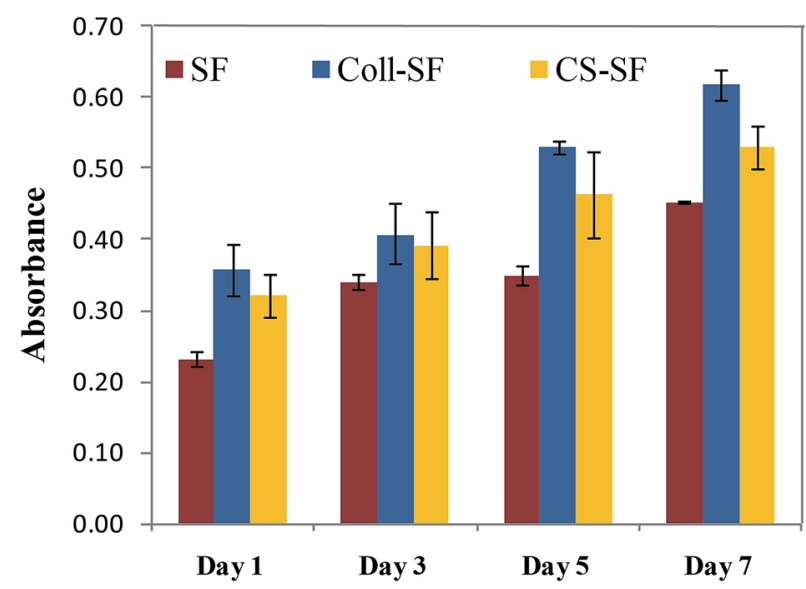

Fig. 5 Cell proliferation assay (MTT assay) of MG 63 cultured on SF, Coll-SF and CS-SF till 7 days. Data are presented as the mean \pm SD of two independent experiments.

Also, the number of live cells observed for modified scaffolds is always higher as compared to the uncoated SF scaffold. The living cell with elongated and spread morphology was most clearly visible on the Coll-SF scaffold as compared to the other two scaffolds used in the study (ESI Fig. S4†). Interestingly, as the experiment progressed, cells formed clumps on CS-SF scaffold.

This clumping was not observed in the SF or Coll-SF scaffold. It has been reported that degree of acetylation of chitosan is responsible for the clustering of cells. ${ }^{41}$ In our study, 15-25\% acetylated chitosan was used to modify the surface and our observations are in accordance with the literature reports. $^{35,41}$
Cell proliferation was analyzed by using MTT assay. As can be seen in Fig. 5, all three scaffolds do support proliferation of the cells. Increased absorbance as a result of proliferation of viable cells were observed with both surface modified scaffolds as compare to unmodified SF scaffold. These results are in-line with those observed in trypan blue and live-dead assay experiments. The viable cell count nearly doubled on the $7^{\text {th }}$ day after incubation. Similar trends in cell proliferation were also observed for the Coll-SF and CS-SF scaffolds.

\section{Cell morphology by actin cytoskeleton staining}

Cellular morphology was evaluated by F-actin cytoskeleton staining with alexafluor 488 phalloidin. Fig. 6 shows the actin cytoskeleton of MG 63 grown on SF, Coll-SF and CS-SF scaffolds. From the images, the significant cell growth with clear morphology of cells with respect to all three scaffolds is clearly visible. More elongated cell morphology with increased number of cells was visible with Coll-SF as compare to SF and CS-SF. Also, for the CS-SF scaffolds, we did observe spreading out of some cells, but the predominant morphology was spherical (ESI Fig. S5†). This variation in morphology of the cells can be attributed to the spread in degree of acetylation in the chitosan used for experimentation. Both the results are in accordance with MTT and live/dead assay results.

In short, data obtained from trypan blue dye extraction method, live/dead assay, actin cytoskeleton staining and cell proliferation assayed by MTT (Fig. 3-6) showed improved performance of the biopolymer coated scaffolds towards cell viability, proliferation and adhesion with retained cell morphology. This is in line with several reports where collagen and chitosan has been shown to improve cell adhesion and 

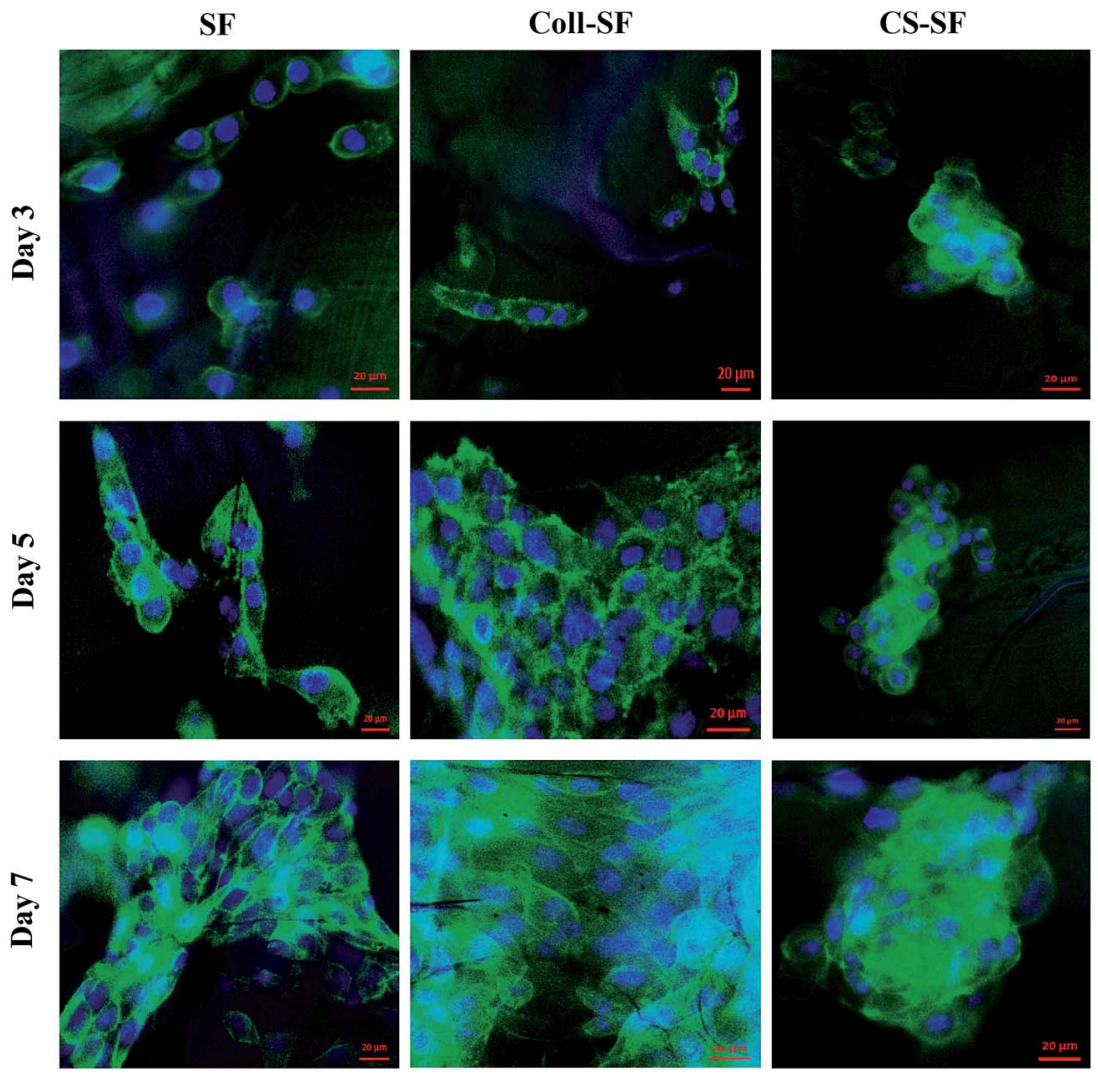

Fig. 6 Actin cytoskeleton staining of MG63 cells with alexafluor phalloidin 488 and nucleus were counter stained with DAPI. Scale bar is $20 \mu$ m.

proliferation. Collagen type I is the dominant component of the ECM in a bone tissue and hence provides the right chemical cues for cell recognition. The integrins present on the cell surface are known to recognize the triple helix structure of collagen. Also, it has been acknowledged that collagen plays an important role in cytoskeleton reorganization and signal transduction, which in turn regulates the cell adhesion and proliferation. ${ }^{46}$ Chitosan has been used in BTE and is shown to induce proliferation of osteoblast cells. The chemical structure of chitosan is similar to glycosaminoglycans (GAGs), which is an important component in ECM. This has been cited as one of the possible reasons for improved adhesion of cells to chitosan. ${ }^{39}$ Our observations support this literature.

\section{Osteogenic differentiation}

Bone is a mineralized connective tissue, which is continuously bioresorbed and neoformed. The formation of new bone tissue requires commitment from the cells towards the osteogenic lineage. The osteoblasts are responsible for synthesis of the bone matrix and as the cells proliferate it shows higher ALP activity and mineral deposition. Thus, in addition to cell adhesion and proliferation, understanding the functioning of cells is also of prime importance in BTE. In this study, we used ALP activity and calcium deposition to monitor osteogenic differentiation of MG 63 cells on unmodified and modified scaffolds.
ALP is an initial marker for the osteogenic differentiation process and is secreted into the ECM, playing a crucial role in bone ECM mineralization.

In our study Fig. 7, we detected measurable ALP activity with all three scaffolds and within the standard calibration curve (ESI Fig. S3 $†$ ). The ALP activity was evident on day 3 for the SF scaffold and was found to be significantly enhanced on day 7. For the CollSF scaffold too, a similar increased ALP activity was observed for day 7. On $3^{\text {rd }}$ and $7^{\text {th }}$ day, the ALP activity between the three types

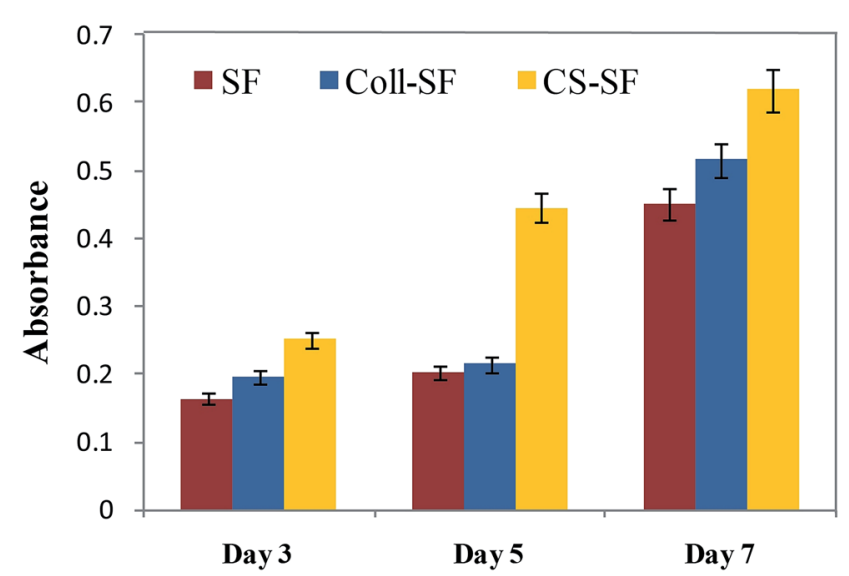

Fig. 7 ALP assay- MG 63 cells cultured on SF, Coll-SF and CS-SF till 7 days. Absorbance was taken at $405 \mathrm{~nm}$ and data are presented as the mean \pm SD of two independent experiments. 


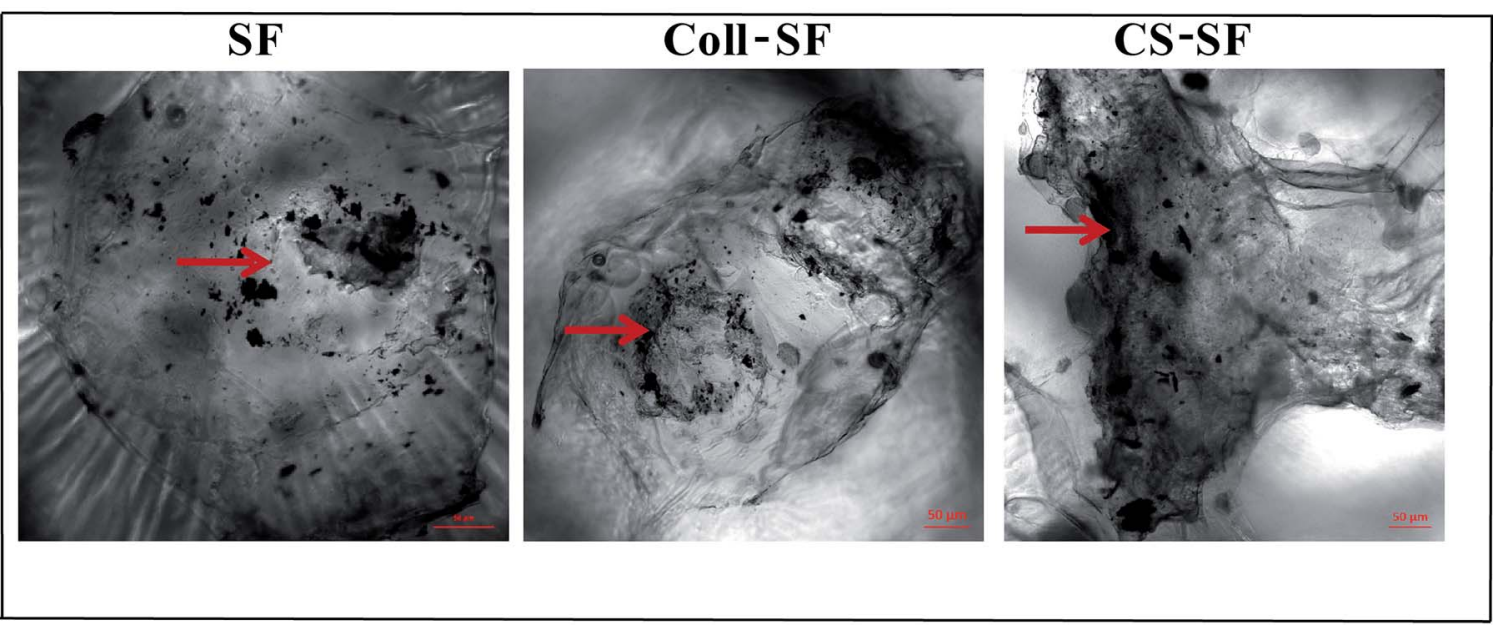

Fig. 8 Calcium depositions by alizarin red S staining. Arrow indicates deposited calcium nodules. All bright field images were taken at same exposure time and scale bar is $50 \mu \mathrm{m}$.

of scaffold studied were comparable, with CS-SF scaffold showing the highest ALP activity. However, on the $5^{\text {th }}$ day, the ALP activity in the CS-SF scaffold was significantly higher than the other two scaffolds studied. Here, the absorbance for CS-SF scaffold was nearly double that of SF and Coll-SF scaffold.

Presence of ALP enzyme is the predetermining early marker as the cells started to differentiate into osteogenic lineage. Throughout the assay, we got higher ALP activity with CS-SF scaffold. The invigorating effect of chitosan on osteogenesis has been extensively reported ${ }^{45,46}$ however the exact mechanism of this osteogenic behavior is unknown. One of the possible reasons that have been discussed is the cationic charge on chitosan. ${ }^{47}$ Also, it has been suggested that high molecular weight $(>10 \mathrm{kDa})$ of chitosan results in improved osteogenic behaviour of MG63 cells. The molecular weight of chitosan used here is $190-310 \mathrm{kDa}$ and thus our observations are in sync with literature. ${ }^{46,48,49}$

Alizarin red S staining was used to detect in vitro extracellular mineral (calcium) deposition as a result of osteoblastic differentiation initiation process. After the $7^{\text {th }}$ day of seeding the MG 63 cells, calcium deposited nodules were detected on all three scaffold Fig. 8. Amount of deposition was not significantly different in SF scaffold and Coll-SF scaffold.

This deposition has been considerably increased as a part of differentiation process with the CS-SF scaffold as is evident in the images. For the Coll-SF scaffolds, Ca deposition is slightly higher than the SF and this improvement can been attributed to the GER sequence in collagen, which acts as an integrin binding site. ${ }^{1,50}$ Also, our ALP activity assay shows moderately increased ALP activity with Coll-SF as compare to SF on $7^{\text {th }}$ day but considerable difference has been noticed with CS-SF. Further, the total amount of Ca deposition was quantified by using $O$ cresolphthalein complexone colorimetric assay (ESI Fig. S6 $\dagger^{\dagger}$ ). Higher Ca content was observed with CS-SF scaffolds as compared to SF and Coll-SF scaffolds. These results are in accordance with the alizarin red S staining studies.

\section{Conclusions}

We report here in vitro cell behavior of osteoblast-like cells on novel SF microparticle scaffolds for applications in load-bearing osteo-regenerative applications. Additionally, we have modified the surface of these scaffolds using natural biopolymers collagen type I and chitosan. Our results suggest that SF microparticle scaffold does support cell attachment, proliferation and differentiation of cells. This behavior can be further enhanced by coating the surface of these scaffolds with collagen type I and chitosan biopolymers. Although the cell attachment, viability and morphology were found to be superior in collagen modified scaffolds, the osteogenic differentiation is better in chitosanmodified scaffolds. The efficacy of these scaffolds for load bearing bone tissue engineering application in vivo is currently underway.

\section{Acknowledgements}

The authors acknowledge BiolMed Innovations Pvt. Ltd. for providing SF micro-particles and SF scaffolds as per the Materials Transfer Agreement signed between BiolMed Innovations and CSIR-National Chemical Laboratory, Pune. We also thank Mr Abhijit Shete for providing help in sample preparation for Scanning Electron Microscopy. We acknowledge Dr MujeebShaikh from Poona College for supporting the project. Also, this work was funded through the CSIR 12th Five Year Plan Project CSC0134.

\section{References}

1 J. Melke, S. Midha, S. Ghosh, K. Ito and S. Hofmann, Acta Biomater., 2015, 31, 1-16.

2 X. Le, G. E. J. Poinern, N. Ali, C. M. Berry and D. Fawcett, Int. J. Biomater., 2013, 2013, 1-16.

3 X. Liu and P. X. Ma, Ann. Biomed. Eng., 2004, 32, 477-486.

4 D. W. Hutmacher, Biomaterials, 2000, 21, 2529-2543. 
5 S.-J. Ding, C.-K. Wei and M.-H. Lai, J. Mater. Chem., 2011, 21, 12793-12802.

6 E. Sachlos and J. T. Czernuszka, Eur. Cells Mater., 2003, 5, 2940.

7 N. Kasoju and U. Bora, Adv. Healthcare Mater., 2012, 1, 393412.

8 L. D. Koh, Y. Cheng, C. P. Teng, Y. W. Khin, X. J. Loh, S. Y. Tee, M. Low, E. Ye, H. D. Yu, Y. W. Zhang and M. Y. Han, Prog. Polym. Sci., 2015, 46, 86-110.

9 A. E. Thurber, F. G. Omenetto and D. L. Kaplan, Biomaterials, 2015, 71, 145-157.

10 L. Meinel, O. Betz, R. Fajardo, S. Hofmann, A. Nazarian, E. Cory, M. Hilbe, J. McCool, R. Langer, G. VunjakNovakovic, H. P. Merkle, B. Rechenberg, D. L. Kaplan and C. Kirker-Head, Bone, 2006, 39, 922-931.

11 S. Saha, B. Kundu, J. Kirkham, D. Wood, S. C. Kundu and X. B. Yang, PLoS One, 2013, 8, 1-10.

12 B. Kundu, R. Rajkhowa, S. C. Kundu and X. Wang, Adv. Drug Delivery Rev., 2013, 65, 457-470.

13 P. Gupta, M. Adhikary, M. Christakiran, M. Kumar, N. Bhardwaj and B. B. Mandal, ACS Appl. Mater. Interfaces, 2016, 8, 30797-30810.

14 S. Ghanaati, R. E. Unger, M. J. Webber, M. Barbeck, C. Orth, J. A. Kirkpatrick, P. Booms, A. Motta, C. Migliaresi, R. A. Sader and C. J. Kirkpatrick, Biomaterials, 2011, 32, 8150-8160.

15 R. E. Unger, A. Sartoris, K. Peters, A. Motta, C. Migliaresi, M. Kunkel, U. Bulnheim, J. Rychly and C. James Kirkpatrick, Biomaterials, 2007, 28, 3965-3976.

16 S. Fuchs, X. Jiang, H. Schmidt, E. Dohle, S. Ghanaati, C. Orth, A. Hofmann, A. Motta, C. Migliaresi and C. J. Kirkpatrick, Biomaterials, 2009, 30, 1329-1338.

17 S. Das, D. Pati, N. Tiwari, A. Nisal and S. Sen Gupta, Biomacromolecules, 2012, 13, 3695-3702.

18 D. L. Kaplan and C. Vepari, Prog. Polym. Sci., 2007, 32, 9911007.

19 A. Nisal, M. Dhanalakshmi, A. Lele, B. L. V Prasad and J. Bellare, Proc. 70th Annu. Tech. Conf. Exhib., Soc. Plast. Eng., Mumbai, India, 6-7 December 2012, pp. 270-275.

20 A. Nisal, C. Kalelkar, J. Bellare and A. Lele, Rheol. Acta, 2013, 52, 833-840.

21 P. Dubey, L. Nawale, D. Sarkar, A. Nisal and A. Prabhune, RSC Adv., 2015, 5, 33955-33962.

22 P. Dubey, S. Kumar, V. K. Aswal, S. Ravindranathan, P. R. Rajamohanan, A. Prabhune and A. Nisal, Biomacromolecules, 2016, 17, 3318-3327.

23 V. Karageorgiou, M. Tomkins, R. Fajardo, L. Meinel, B. Snyder, K. Wade, J. Chen, V. Vunjak-Novakovic and D. L. Kaplan, J. Biomed. Mater. Res., Part A, 2006, 33, 324-334. 24 H. J. Chung and T. G. Park, Adv. Drug Delivery Rev., 2007, 59, 249-262.

25 W. Zhang, C. Zhu, D. Ye, L. Xu, X. Zhang, Q. Wu, X. Zhang, D. L. Kaplan and X. Jiang, PLoS One, 2014, 9, 1-9.

26 B. B. Mandal, A. Grinberg, E. Seok, B. Panilaitis and D. L. Kaplan, Proc. Natl. Acad. Sci. U. S. A., 2012, 109, 76997704 .
27 F. Ak, Z. Oztoprak, I. Karakutuk and O. Okay, Biomacromolecules, 2013, 14, 719-727.

28 A. M. Collins, N. J. V Skaer, T. Gheysens, D. Knight, C. Bertram, H. I. Roach, R. O. C. Oreffo, S. Von-Aulock, T. Baris, J. Skinner and S. Mann, Adv. Mater., 2009, 21, 75-78.

29 A. Nisal, P. Venugopalan and N. Sinha, CSIR-National Chemical Laboratory, WO2014125505 A1, 2014, pp. 1-10.

30 A. Nisal, P. Venugopalan and B. Khude, CSIR-National Chemical Laboratory, WO2016110873 A1, 2016, pp. 1-9.

31 B. Dhandayuthapani, Y. Yoshida, T. Maekawa and D. S. Kumar, Int. J. Polym. Sci., 2011, 290602.

32 M. Vandrovcová, T. Douglas, D. Hauk, B. GrössnerSchreiber, J. Wiltfang, L. Bačáková and P. H. Warnke, Physiological Research, 2011, 60, 797-813.

33 A. M. Ferreira, P. Gentile, V. Chiono and G. Ciardelli, Acta Biomater., 2012, 8, 3191-3200.

34 M. H. Lee, C. You and K. H. Kim, Materials, 2015, 8, 11501161.

35 J. Y. Lee, S. H. Nam, S. Y. Im, Y. J. Park, Y. M. Lee, Y. J. Seol, C. P. Chung and S. J. Lee, J. Controlled Release, 2002, 78, 187197.

36 J. Venkatesan and S. K. Kim, Mar. Drugs, 2010, 8, 2252-2266.

37 A. R. Costa-Pinto, R. L. Reis and N. M. Neves, Tissue Eng., Part $B, 2011,17,331-347$.

38 S. Zeng, L. Liu, Y. Shi, J. Qiu, W. Fang, M. Rong, Z. Guo and W. Gao, PLoS One, 2015, 10, e0128658.

39 R. LogithKumar, A. KeshavNarayan, S. Dhivya, A. Chawla, S. Saravanan and N. Selvamurugan, Carbohydr. Polym., 2016, 151, 172-188.

40 C. Li, C. Vepari, H.-J. Jin, H. J. Kim and D. L. Kaplan, Biomaterials, 2006, 27, 3115-3124.

41 I. F. Amaral, P. Sampaio and M. A. Barbosa, J. Biomed. Mater. Res., Part A, 2006, 76, 335-346.

42 B. Liu, S. Wu, L. Han and C. Zhang, Int. J. Mol. Med., 2015, 1572-1582.

43 M. Yang, Y. Shuai, W. He, S. Min and L. Zhu, Int. J. Mol. Sci., 2012, 13, 7762-7775.

44 C. Pautke, M. Schieker, T. Tischer, A. Kolk, P. Neth, W. Mutschler and S. Milz, Anticancer Res., 2004, 24, 37433748.

45 Y. Zhang, M. Ni, M. Zhang and B. Ratner, Tissue Eng., 2003, 9, 337-345.

46 A. Fakhry, G. B. Schneider, R. Zaharias and S. Şenel, Biomaterials, 2004, 25, 2075-2079.

47 X. Yang, X. Chen and H. Wang, Biomacromolecules, 2009, 10, 2772-2778.

48 K. Lee, G. Jin, C. H. Jang, W.-K. Jung and G. Kim, J. Mater. Chem. B, 2013, 1, 5831.

49 S. Sundelacruz and D. L. D. L. Kaplan, Semin. Cell Dev. Biol., 2009, 20, 646-655.

50 C. G. Knight, L. F. Morton, D. J. Onley, A. R. Peachey, J. Messent, P. A. Smethurst, S. Danny, R. W. Farndale, J. Michael, C. G. Knight, L. F. Morton, D. J. Onley, A. R. Peachey, A. J. Messent, P. A. Smethurst, D. S. Tuckwell, R. W. Farndale and M. J. Barnes, J. Biol. Chem., 1998, 273, 33287-33294. 